\title{
CORONARY HEART DISEASE IN SEVEN RACIAL GROUPS IN SINGAPORE
}

\author{
BY \\ C. S. MUIR \\ From the Department of Pathology, University of Malaya \\ Received February 16, 1959
}

The purpose of this communication is to examine the pattern of coronary heart disease over the years 1948 to 1957 inclusive, as seen in the mortuary of the General Hospital at Singapore in 19,415 consecutive autopsies, and to determine whether there are racial differences. The macroscopic data considered relevant were transferred from the post-mortem protocols on to a specially prepared proforma in all those cases in which the principal cause of death was given as coronary heart disease. The series does not include other cases in which coronary heart disease was an incidental finding.

The Island of Singapore and its Population. Singapore, an island of some 217 square miles, lies one degree north of the Equator and 104 degrees east of Greenwich. The climate is equable, the average temperature being $85^{\circ} \mathrm{F}$. and the average relative humidity 83 per cent. There are no seasons. On the Island live some one and a half million people of varying races, religions, customs, and dietary habits.

When Thomas Stamford Raffles landed on the Island in 1819 the population was in the region of 150, all Bugis Malay. In 1824 when the Island was formally ceded to the East India Company, it had risen to 10,000. Free immigration continued, mainly from China and India, until about 1939. Since then the polyglot populace has rapidly increased until it has reached the figures shown in Table I.

TABLE I

Population and Necropsies from Coronary Heart Disease in Different Racial Groups

\begin{tabular}{|c|c|c|c|c|c|c|c|c|c|c|c|}
\hline & & & & & Chinese & $\begin{array}{l}\text { Indians + } \\
\text { Pakistanis }\end{array}$ & Malays & Euras. & Europ. & Others & Totals \\
\hline 1947 census & .. & . & .. & . & 729,473 & 68,967 & 113,803 & 9,110 & 9,279 & 7,512 & 938,144 \\
\hline 1957 census & . & . & . & . & $1,127,000$ & 115,000 & 180,000 & 15,000 & 22,000 & 15,000 & $1,474,000$ \\
\hline Mean popul & ion & $\cdots$ & . & . & 928,200 & 92,000 & 146,900 & 12,000 & 15,600 & 11,300 & $1,206,000$ \\
\hline Necropsies & th $\mathbf{C}$ & H.D. & . & . & 238 & 244 & 35 & 12 & 29 & - & 558 \\
\hline \multicolumn{5}{|c|}{$\begin{array}{l}\text { Deaths from Cor.H.D. per } 1000 \text { per } \\
\text { annum }\end{array}$} & 0.026 & 0.265 & 0.024 & $0 \cdot 100$ & $0 \cdot 186$ & - & 0.046 \\
\hline
\end{tabular}

\section{Deaths from Coronary Heart Disease}

Table I shows, by race, the population distribution in the year 1947 and the estimated numbers in the 1957 census. The latter numbers were obtained by applying the end 1956 percentage distribution by race to the 1957 census total population figure of $1,474,000$. The mean was derived and the 
post-mortem incidence of coronary heart disease expressed as so many per thousand per annum for each racial group.

Unfortunately, neither in the 1947, nor in the 1957 census, was enquiry made as to religion. The latest figures available are for 1931, and these refer, not to Singapore alone, but to the Straits Settlements, which comprised the Islands of Singapore and Penang, with the present State of Malacca. Although it is realized that these proportions are probably no longer accurate they are applied in Table II since it is felt that they can, faute de mieux, be used to give a rough Indian/Indian Muslim ratio.

Table II shows the number of deaths from coronary heart disease within the group Indians and Pakistanis (Table I), expressed as so many per thousand per annum. The Indian Muslim would appear to be twice as liable to die from coronary heart disease, as his non-Muslim compatriot, and twenty times more liable than the Chinese or the Muslim Malays.

TABLE II

Necropsies with Coronary Heart Disease in Different Religious Groups in Indians and Pakistanis

\begin{tabular}{|c|c|c|c|c|c|c|c|c|c|c|c|c|}
\hline Religion .. & . & $\cdots$ & . & . & $\cdots$ & Hindu & Christian & Buddhist & Others & Muslim & Sikh & Total \\
\hline \multirow{2}{*}{ Per thousand } & \multirow[b]{2}{*}{$\cdots$} & \multirow{2}{*}{$\cdots$} & \multirow{2}{*}{$\cdots$} & \multirow{2}{*}{$\cdots$} & \multirow{2}{*}{$\cdots$} & $\underbrace{709 \cdot 1}$ & $64 \cdot 3$ & $3 \cdot 0$ & $3 \cdot 4$ & \multirow[b]{2}{*}{$187 \cdot 5$} & \multirow[b]{2}{*}{$32 \cdot 7$} & \multirow[b]{2}{*}{$1000 \cdot 0$} \\
\hline & & & & & & \multicolumn{4}{|c|}{$779 \cdot 8$} & & & \\
\hline \multicolumn{4}{|c|}{ Estimated number for each religion } & . & . & \multicolumn{4}{|c|}{72,000} & 17,000 & 3,000 & 92,000 \\
\hline \multicolumn{4}{|c|}{ Necropsies with Cor.H.D. } & $\cdots$ & $\cdots$ & \multicolumn{4}{|c|}{160} & 74 & 10 & 244 \\
\hline \multicolumn{6}{|c|}{ Deaths from Cor.H.D. per 1000 per annum. . } & \multicolumn{4}{|c|}{$0 \cdot 222$} & 0.435 & 0.333 & $0 \cdot 265$ \\
\hline
\end{tabular}

\section{Deaths in which a Thrombus was Found (Thrombus Positive Group)}

A thrombus was discovered in the coronary arteries of 242 persons, of whom $16(7 \%)$ were women. For the 88 Chinese in this group, the mean age at death was $51.9 \pm 11 \cdot 1$ years; for the 74 Indians $44 \cdot 3 \pm 10 \cdot 1$ years; for the 33 Indian Muslims $46 \cdot 4 \pm 10 \cdot 5$ years; for the 18 Malays $47 \cdot 1 \pm 8 \cdot 7$ years; for the 7 Eurasians $47 \cdot 3 \pm 11 \cdot 5$ years; for the 16 Europeans $51 \cdot 1 \pm 9 \cdot 2$ years; and for the 6 Sikhs $50 \cdot 0 \pm 10 \cdot 9$ years. The mean for all races was $48 \cdot 1 \pm 11.5$ years. The average age at death for Indians, Indian Muslims, and Malays is thus significantly less than for Chinese (respective O.D./S.E. ratios being $4 \cdot 6,3 \cdot 3$, and $2 \cdot 0$ to 1 ). There is no significant difference between Indians, Indian Muslims, and Malays.

More Indians and Indian Muslims die from coronary occlusion in the fourth decade than do Chinese, 32 and 30 per cent instead of 15 per cent. Bland and White (1951) reviewing 461 cases of clinical myocardial infarction found that 22 per cent were below the age of 50 : in this series the respective percentages, below the age of 50, for Chinese, Indians, Indian Muslims, Malays, and Europeans are $41,68,60,68$, and 37 respectively.

The peak incidence in the series of Bland and White (1951) in America was in the decade 50-59, in that of Peel (1955) in Scotland at ages 55-59, and in that of Weiss and Gray (1954) in the American Negro in the decade 60-69. Vakil (1949) in his series, principally Indian Hindus, found it to be in the decade $40-49$, the mean age at death being 49.4 years. In this series the peak incidence in the Chinese is in the decade 51-60, in the Malay 41-50, and in both Indians and Indian Muslims in the decade $36-45$.

Table III shows, by race, the site of thrombosis in the thrombus positive group. Wood (1956) summing up the observations of several writers, notes that the anterior descending branch of the left coronary artery is affected in 66-75 per cent of cases, the left circumflex in 5-33 per cent, and the right in 25-40 per cent: thrombosis of the left main trunk, he states, is rare (this series $8 \%$ ). The mean figures in this series lie within these values. There appears to be a racial difference in the number 
TABLE III

The Site of The Thrombus by Racial Groups

\begin{tabular}{|c|c|c|c|c|c|c|c|c|c|c|}
\hline $\begin{array}{ll}\text { Artery } & \mathrm{R} \\
\end{array}$ & & $\begin{array}{l}\text { Chinese } \\
\text { No. \% }\end{array}$ & $\begin{array}{l}\text { Indian } \\
\text { No. } \%\end{array}$ & $\begin{array}{l}\text { Ind. Mus. } \\
\text { No. } \%\end{array}$ & $\begin{array}{c}\text { Malay } \\
\text { No. } \%\end{array}$ & $\begin{array}{l}\text { Euras. } \\
\text { No. } \%\end{array}$ & $\begin{array}{l}\text { Euro } \\
\text { No. }\end{array}$ & & $\begin{array}{c}\text { Sikh } \\
\text { No. } \%\end{array}$ & $\begin{array}{r}\text { Total } \\
\text { No. } \% \frac{\%}{\%}\end{array}$ \\
\hline L.D. & . & $44 \quad 50$ & $\begin{array}{ll}51 \quad 69\end{array}$ & $\begin{array}{ll}20 & 61\end{array}$ & $10 \quad 56$ & $7 \quad 100$ & 8 & & $4 \quad 67$ & 144 \\
\hline L.M. & . & 5 & $7 \quad 10$ & $\begin{array}{ll}6 & 18\end{array}$ & 16 & $-\quad-$ & 21 & 13 & -- & 20 \\
\hline Circ. $\quad .$. & .. & 89 & 1 & 3 & -- & $-\quad-$ & - & - & 116 & 11 \\
\hline .. & . & $20 \quad 23$ & 6 & $5 \quad 15$ & $4 \quad 22$ & $-\quad-$ & 21 & 13 & $1 \quad 16$ & $38 \quad 16$ \\
\hline L.D. +R. & .. & 78 & 4 & $-\quad-$ & $2 \quad 11$ & $-\quad-$ & 1 & 6 & -- & 14 \\
\hline L.M. +R. & .. & 11 & $\begin{array}{ll}1 & 1 \\
\end{array}$ & -- & 16 & $-\quad-$ & - & - & -- & 3 \\
\hline L.D. +C. & .. & 11 & -- & 13 & -- & $-\quad-$ & - & - & -- & 2 \\
\hline L.M.+L.D. & .. & 2 & 1 & -- & -- & $-\quad-$ & 21 & 13 & -- & 5 \\
\hline C. +R. .. & .. & -- & -- & -- & -- & $-\quad-$ & 1 & 6 & -- & 0.5 \\
\hline Not stated & .. & 11 & 4 & -- & -- & $-\quad-$ & - & - & -- & 4 \\
\hline Total & .. & 88 & 74 & 33 & 18 & 7 & 16 & & 6 & 242 \\
\hline $\begin{array}{l}\text { Total L.D. } \\
\text { Total R. }\end{array}$ & .. & $\begin{array}{ll}54 & 61 \\
28 & 32\end{array}$ & $\begin{array}{ll}56 & 76 \\
11 & 15\end{array}$ & $\begin{array}{rr}21 & 63 \\
5 & 18\end{array}$ & $\begin{array}{rr}12 & 66 \\
7 & 39\end{array}$ & $\begin{array}{r}7100 \\
-\quad-\end{array}$ & $\begin{array}{ll}8 & 7 \\
1\end{array}$ & $\begin{array}{r}73 \\
9\end{array}$ & $\begin{array}{ll}5 & 71 \\
1 & 14\end{array}$ & $\begin{array}{rr}163 & 67 \\
53 & 22\end{array}$ \\
\hline
\end{tabular}

Cor.H.D. = Coronary heart disease.

L.D. = Anterior descending branch of left coronary artery.

L.M. = Main trunk of the left coronary artery.

Circ. or $\mathbf{C} .=$ Circumflex branch of left coronary artery.
R.= Right coronary artery.

O.D.= Observed difference.

S.E. $=$ Standard error.

of thrombi found in the right coronary artery, if Chinese and Indians be compared. The ratio O.D./S.E. is 3.5 to 1 for thrombi in the right coronary artery alone, and 2.5 to 1 for thrombi in the right coronary artery both alone and in combination. The figures for Indians appear rather lower than usual, but do not differ significantly from the mean. There are no other significant differences.

Macroscopic necrosis was observed in 114 of the 242 hearts in this group. Although thrombosis without infarction has been observed before, Wood (1956) giving the figure 20 per cent, the high incidence in this series $(53 \%)$ is thought to reflect the fact that only macroscopic necrosis has been recorded. The necrosis was mainly anterior in $81(71 \%)$, mainly posterior in $31(27 \%)$, the site not being specified in a further $2(2 \%)$. In Indians there was a smaller proportion of posterior infarctions $(19 \%)$, reflecting the diminished frequency of thrombosis in the right coronary artery (Table III). This distribution agrees with the observations of Wartmann and Hellerstein (1948) who found chiefly anterior infarctions in 72 per cent of their cases.

Morbid Anatomy. In this group the coronary ostia were involved in 6 per cent. Subintimal hæmorrhage had occurred in 4 per cent while the thrombus was found on an ulcerated atheromatous plaque in 12 per cent. Gross calcification of the arterial wall was present in 21 per cent. There was evidence of a prior infarction in 15 per cent. The atheromatous lesions in the coronary vessels were classed as severe in 45 per cent, as moderate in 26 , and as slight in 13 per cent: in a further 1 per cent atheroma was absent, and no record had been made in the remainder. There were no significant racial differences.

Myocardial fibrosis visible to the naked eye was noted in $124(51 \%)$. In the main the thrombus formed in the artery that supplied the fibrotic area of heart. The Indian Muslim, however, deviated significantly from this rule, a phenomenon for which no explanation can be offered. 
Rupture of the heart was seen in 7 per cent of cases, a cardiac aneurysm in 2 per cent, thromboembolic phenomena in 2 per cent, and mural thrombus in 6 per cent. In the Indian Muslim the incidence of these complications was much higher than in the other races, respective figures being $18,12,6$, and 30 per cent, differences that are statistically significant.

The mean incidence of these complications is much less than in most reported series. Wood (1956) regards the upper limit of cardiac rupture as being 15 per cent. Hellerstein and Martin (1947), adding up the findings of eleven workers, record thromboembolic phenomena in 11.5 per cent, and intramural thrombi in 40 per cent. Figures for cardiac aneurysm vary enormously depending largely on what the author regards as an aneurysm: Cleland (1949) gives 4 per cent in his Australian series.

\section{Deaths in which No Thrombus was Found (Thrombus Negative Group)}

No thrombus was found in the coronary arteries of 316 persons of whom $25(8 \%)$ were women. In 150 Chinese the mean age at death was $51 \cdot 1 \pm 12 \cdot 1$ years, in 86 Indians $46 \cdot 9 \pm 11 \cdot 1$ years, in 41 Indian Muslims $44 \cdot 6 \pm 7.5$ years, in 17 Malays $46 \cdot 2 \pm 10.8$ years, in 5 Eurasians $49 \cdot 8 \pm 8 \cdot 8$ years, in 13 Europeans $57 \cdot 5 \pm 13.2$ years, and in 4 Sikhs $59 \cdot 0 \pm 8 \cdot 8$ years. The mean for all races was $48 \cdot 6 \pm 11 \cdot 5$ years.

The average age at death in the thrombus negative group for Indians and Indian Muslims is significantly lower than in the Chinese, the O.D./S.E. ratio being respectively $2 \cdot 7$ and $4 \cdot 2$ to 1 . There is no statistically significant difference between Malays, Indians, and Indian Muslims.

By the age of 50, 49 per cent of the Chinese, 69 per cent of the Indians, 60 per cent of the Indian Muslims, and 59 per cent of the Malays in this group had died. The peak incidence was in the decade 46-55, with the exception of the Indian where it was in the decade 41-50.

Comparison with the thrombus positive group reveals a remarkable similarity. Vakil (1949) noted a similar picture when he compared his coronary occlusion and angina pectoris groups.

Morbid Anatomy. Myocardial necrosis was found in 140 of the hearts in this group (44\%). Rupture of the myocardium was noted in 4 per cent, a cardiac aneurysm in 2 per cent, mural thrombus in 3 per cent, and thrombo-embolic phenomena in 1 per cent. There were no significant racial differences.

Atheroma in the coronary vessels was found to be severe in 69 per cent, moderate in 19 per cent, slight in 7 per cent, and absent in 2 per cent : although the cause of death was given as coronary heart disease, no note had been made about the state of the coronary vessel wall in the remainder. The arteries were occluded by atheroma in $83(26 \%)$ cases, but in the Indian Muslim they were occluded in 37 per cent. Macroscopic fibrosis of the myocardium was found in 59 per cent of the thrombus negative group, being predominantly anterior in 67 per cent and predominantly posterior in 19 per cent: in the remaining 13 per cent the site of the fibrosis was not stated. The higher incidence of fibrosis in the thrombus negative group is a reflection, one presumes, of the larger number showing severe atheroma.

\section{Association with CARDiac ENLARgEMENT}

Although the normal heart weight for most of the population of Singapore is probably about $350 \mathrm{~g}$., only the hearts weighing $450 \mathrm{~g}$. or more are classed as enlarged for the purposes of this paper. 139 enlarged hearts $(25 \%)$ were found, on this criterion. There were no racial differences, nor were more thrombi found in this group. Bartels and Smith (1932) noted hypertrophy in 88 per cent and Cleland (1949) in 60 per cent of infarcted hearts examined post mortem.

It has been held that the enlargement seen in infarcted hearts has been due to a co-existent hypertension. Master (1954) examined 500 men clinically who suffered from coronary occlusion and concluded that, allowing for the natural increase of blood pressure with ageing, the enlargement was due to coronary insufficiency rather than to hypertension. He also showed that hypertension does not predispose to the formation of a cardiac aneurysm. But Friedberg and Sohval (1949) 
examined the hearts post mortem of 100 cases of acute coronary occlusion and found that there was no increase in heart size except in those with an ante-mortem record of hypertension. It is regretted that in this series no ante-mortem data are available for most of the patients, hence no opinion can be given to this question.

\section{Coronary Heart Disease in Women}

Estimates as to the incidence of coronary heart disease in women vary considerably. Weiss and Gray (1954) found the male/female ratio for their series of Negroes to be $1 \cdot 1$ to 1 , Clawson (1941) found it $4 \cdot 2$ to 1 , Vakil (1949) 8.6 to 1 , and Jayewardene and Jayesekere (1954) $10 \cdot 2$ to 1. In this series $41(7 \%)$ were women, a male/female ratio of 12.5 to 1 . However, only 34 per cent of the necropsies in this series of 19,415 were performed on female subjects.

There were 16 women in the thrombus positive group, 12 of whom were Chinese. The mean age at death for the Chinese was $49 \cdot 6 \pm 11 \cdot 5$ years and for the $16,50 \cdot 2 \pm 10 \cdot 2$ years. In the thrombus negative group there were 25 women, including 19 Chinese and 5 Indians. The mean age at death for the Chinese was $55 \cdot 9 \pm 15 \cdot 6$ years, for the Indians $59 \cdot 1 \pm 13 \cdot 2$ years, and for the whole group $57 \cdot 6 \pm 14 \cdot 7$ years.

Most authors seem agreed that, whereas men show a peak incidence of coronary heart disease (in the Occident usually in the sixties), the incidence in women gradually rises from the fifties onwards, until in the seventies it is equal to, or surpasses, that of men (Peel, 1955). In this series, 58 per cent of the Chinese women with thrombi had died before the age of 50 (men $38 \%$ ) the peak incidence being in the decade 41-50 (men, 51-60). In the thrombus negative group 47 per cent had died before the age of 50 (men, $49 \%$ ) the peak incidence being in the decade 41-50 (men 46-55). Vakil (1949) found the peak incidence for women to be in the decades $40-60$, and 46 per cent of his 26 women had died before attaining 50 years.

From the evidence available it seems likely that the age distribution of coronary heart disease in the East is somewhat different to that reported in the West. In the thrombus positive group the ages ranged from 26 to 66 years. The youngest case is of some interest, being five months pregnant at the time of death. Autopsy revealed a large recent thrombus in the right main coronary artery $4 \mathrm{~cm}$. from its commencement, coronary vessels that appeared normal, and no abnormality of the genital tract. In $5(31 \%)$ of the thrombus positive cases the thrombus was noted to be old (males $13 \%$ ). In the thrombus negative group the youngest case, aged 27 , showed severe atheroma of both coronary arteries, anterior fibrosis and necrosis of the myocardium, with a recent rupture $2 \mathrm{~cm}$. long at the apex.

\section{AsSOCIATION WITH EFFORT}

Only 11 of the 242 deaths $(5 \%)$ in the thrombus positive group were noted as being associated with physical effort. Of these, 4 occurred in Indian Muslims. Seven deaths occurred in the lavatory. Phipps (1936) noted exertion in 13 per cent of his cases; Master et al. (1937) noted severe effort in 2 per cent and moderate effort in 9 per cent. These low figures do not accord with the experience of all (Smith et. al., 1942; Yater et al., 1948).

Surprisingly, an even smaller number, i.e., only seven, in the thrombus negative group died during or shortly after physical exertion: of these, five were Malays. Eight deaths occurred in the lavatory.

\section{Selection AND Bias}

At the outset of this investigation, it was felt that it would be better to consider only those cases that came within the jurisdiction of H.M. Coroner, it being argued that violent and sudden deaths were likely to affect all races in much the same proportions. This did not prove to be so and this group was found to be heavily weighted by Indians and Indian Muslims. Part, but not all, of this bias was due to the large numbers of deaths from coronary heart disease within these two racial groups. 
Consideration of those dying in hospital revealed many points of bias. For religious reasons virtually no post mortems are obtained in Malays or Indian Muslims, hence this series is unduly weighted by Chinese. It is much easier to obtain permission to examine a child than an adult. A necropsy may be performed on a body not claimed within 24 hours of death, consequently many children, but few adults, come to morbid examination under this ruling.

It was felt, therefore, that rather than attempt to disentangle these many factors, with probably results of dubious value, it would be better to relate all figures obtained to the total number of post mortems performed in the period 1948-57 inclusive. Despite this the post-mortem figures probably reflect the relative racial proportions quite well. During the nine years 1948-56, 1178 deaths were registered by the Registrar-General as being due to "arteriosclerotic heart disease, including coronary disease." This is equivalent to $1 \cdot 14$ per cent of the 103,464 deaths in that period, or to $0 \cdot 11$ deaths per 1000 population per annum. This latter figure is $2 \cdot 4$ times the mean autopsy rate for coronary heart disease (Table I).

Unfortunately there is no racial breakdown for these figures, but, should it be assumed that the 626 persons who were not autopsied (i.e. 1178-552) were all of Chinese race, the ratio Indians+ Pakistanis/Chinese for deaths from coronary heart disease would be $0 \cdot 265 / 0 \cdot 093=2 \cdot 85 / 1$, a figure that is still highly significant (O.D./S.E. $=15 / 1)$.

\section{RISE IN INCIDENCE}

Many reports have come from the Occident purporting to show a steady rise in the incidence of coronary heart disease over the past 30 years: Ryle and Russell (1949) in the United Kingdom, Davidson (1953) in Australia, Denny (1936) and Hedley (1939) in the United States of America.

In Singapore, pre-war autopsy figures are not available as all records were destroyed during the Japanese occupation. The records of the Registrar General (Singapore) were however maintained during this period. Fig. 1 shows the rise in the number of deaths from coronary heart disease, as

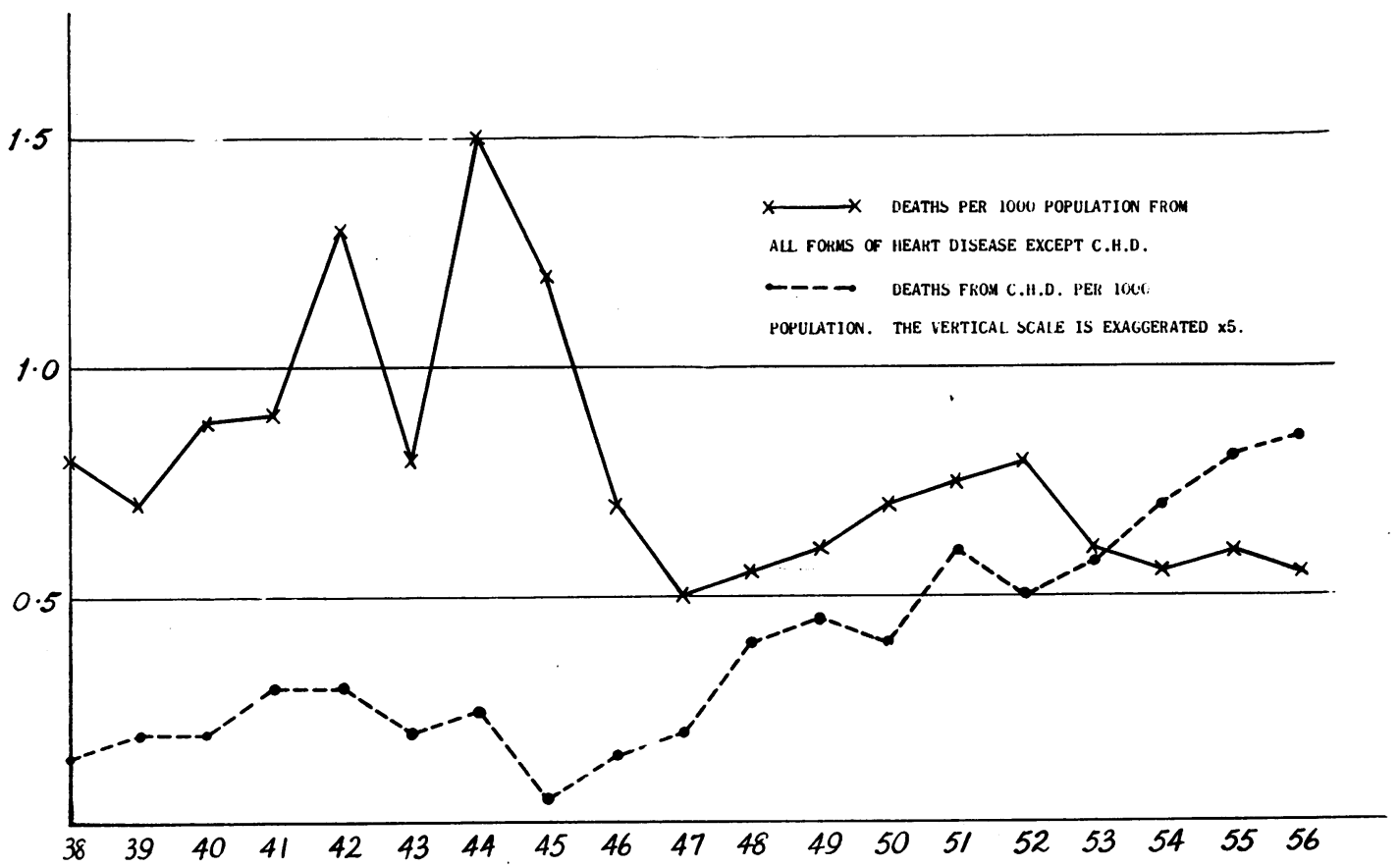

FIG. 1.-The number of deaths from coronary heart disease, as recorded by the Registrar General (Singapore) per 1000 population, related to the numbers dying from all other forms of heart disease per 1000 population during the decades 1938-47 and 1948-57. 
recorded by the Registrar General (Singapore), per 1000 population, related to the numbers dying from all other forms of heart disease per 1000 population during the decades 1938-47 and 1948-57.

The mean incidence is 0.16 per cent of all deaths in the former decade, and 1.03 per cent in the latter, but the incidence of deaths from other forms of heart disease is much lower. The percentage incidence is also falsely low in the decade 1937-47 due to the increased incidence of, and death rate from, tuberculosis, beri-beri, and malaria. There is nevertheless a large increase over the twenty years.

Post-mortem figures since the War show that coronary heart disease accounted for 2.9 per cent of all deaths, or 21.2 per cent of all cardiac deaths (Muir, 1958). The diminution in incidence during the War years will be readily observed. In this period of privation, coronary heart disease was held to be much less common (Subrahmanyam, 1958) and this was also the experience in other countries, e.g. Norway (Malmros, 1950); this decrease was attributed to a diminished intake of foods rich in cholesterol. Schornagel (1953) noted a fall in the incidence of coronary sclerosis in Rotterdam, the lowest figures, as in Singapore, being found in 1944 and 1945.

From the neighbouring territory of Malaya, Marsden (1957) remarks that "coronary disease occurs and is well known." In Malaya over the years 1948-56 the total hospital in-patient population was $2,056,270$. During this period 940 cases of coronary heart disease were treated, an incidence of 0.46 per 1000 . Of these 39 per cent died. General statistics for the whole country are unreliable as many deaths (in $1956,81 \%$ ) are not certified by medical practitioners.

In both territories there has been a steady increase in the numbers with this disease treated in hospital. In 1948, in Singapore there were 6, and in the Federation, 2 patients per 10,000 hospital admissions: by 1956 the corresponding figures were 30 and 10 respectively-a considerable rise.

\section{Discussion}

Coronary heart disease is still stated to be rare among the Chinese (White, 1951). Snapper (1941) has emphasized the rarity of coronary arteriosclerosis in North China, believing this to be due to a low intake of fats containing saturated fatty acids. Tung (1948), reporting 18 cases of coronary thrombosis, remarked that up to that time no paper on coronary disease in China had been published: 15 of his patients came from the upper social and economic strata of Shanghai and might well be expected to have a much higher intake of richer foods. Foster (1930) noted the rarity of arteriosclerosis in patients attending the Yale-Hunan Hospital and found only one case of angina pectoris in 4000 . He noted the low blood pressure of the local population and found that the blood pressure of Americans living there gradually fell too. Houston (1928) has noticed that the blood pressure of immigrant Chinese in America rises.

Vakil (1949) has described coronary heart disease in Bombay. $1860(6 \%)$ of the admissions to the King Edward Memorial Hospital suffered from some form of organic heart disease, and of these 250 had some form of coronary heart disease, i.e. 13.5 per cent of all cardiac cases. The highest incidence was observed "at least a decade earlier than in reported Western statistics. The same has been the experience of numerous colleagues in this country. . . " He studied the question of racial incidence and concluded that "the incidence of coronary disease is higher in the minority communities," i.e. Indian Muslims, Indian Christians, Parsees, and Jews. He does not relate his figures to the population at large.

Wijeyesekera (1954), studying clinically 100 cases of myocardial infarction in Ceylon, found that, contrary to most other countries, the incidence was highest in the lower income groups, but his series did not include nursing home cases, which may account for the difference. He found the incidence highest among Eurasians and Burghers, intermediate in the Tamils, and least in the Sinhalese, the respective figures being $0 \cdot 26,0 \cdot 12$, and 0.06 per 1000 of population. The peak incidence was in the decade 50-60, 38 per cent dying below the age of 50. These figures are almost identical with those of Jayewardene and Jayesekere (1954), who find the post-mortem incidence in Colombo to be 368 in 3632 consecutive autopsies, both hospital and judicial, i.e. 10 per cent.

Thus, there is a body of evidence to suggest that the Chinese in China are not prone to coronary 
heart disease. In Singapore it has been shown that the Chinese element of the population while not by any means immune, is very much less liable to coronary heart disease than the Indian, Indian Muslim, Eurasian, and European communities.

Vakil (1949) has shown that the Indian Muslim is probably more liable to coronary disease than the Hindu. This is borne out in Singapore. Ruffer (1921) who performed 800 autopsies on Muslim pilgrims dying on the road to Mecca found coronary atheroma to be as common as in Europeans. Yet from our figures in Singapore, the Muslim Malay dies but rarely from coronary heart disease. It would in this context be interesting to examine the incidence of coronary and other heart disease in a Muslim Chinese community such as exists in West China and relate it to non-Muslim Chinese nearby. Such a survey would show whether the Muslim way of life has a role in the causation of coronary heart disease.

There may be some factor that makes coronary atheroma more dangerous to one racial group than another, for as Davies (1948) remarks "In Africa one of the puzzling features of atheroma in Africans is the rarity of coronary thrombosis." Similarly, Becker (1946) finds that the incidence of atheromatosis in Bantu and Coloured subjects is low, for in his series of 3000 consecutive postmortems, atheromatosis was responsible for the death of only 11 subjects, and only one of these was due to coronary thrombosis.

The negro in America has long been held to be less liable to coronary heart disease than the American white (Johnston, 1936), but Holoubek (1945), Yater et al. (1948) and others have shown that this is probably not so. Whether this apparent increase is true or represents a higher standard of living and medical care, no one seems to know.

Müller (1935) found the post-mortem incidence of atherosclerosis in Java, where there is also a multiracial population, to be the same as in Holland, noting that prior to this date no cases of either coronary thrombosis or coronary sclerosis had been encountered in the post-mortem material of Batavia (Djakarta) and Sourabaya. Zuidema, writing in 1952, describes 79 cases of clinical coronary thrombosis occurring in Europeans, Chinese, and Indonesians in Djakarta, most of whom came from the higher income groups.

It is tempting to ascribe the differences found to dietary habit. In Singapore, the diet of most Chinese is based on rice. Much of the food is greasy, being cooked in a vegetable oil (peanut), less commonly in pig lard. Fish is probably the staple source of protein, pork being reserved for festivals and egg and milk consumption being very low. The diet of the non-Muslim Indian from the North, and of the Sikh, is based on chuppattis made from atta flour: he drinks a large amount of milk, eats little meat, and his cooking is done in ghee (clarified butter). The Southern non-Muslim Indian subsists on rice, cooked vegetables, and a very hot curry, usually of fish each day; mutton is usually eaten once a week; and the cooking is done in linseed or coconut oil. The Indian Muslim likes very oily food, which is nearly all cooked in ghee; he consumes more mutton than anybody else, usually the fatter cuts, eating meat about three days a week; and he also favours a sedentary occupation. The Malay lives on fish and rice, usually curried, rarely eating meat; his cooking is done in coconut oil.

It will be appreciated that the diets outlined are subject to considerable variation, especially in the more wealthy families. The more exact composition of these diets, with particular reference to the degree of saturation of the fats, will be the subject of a further communication. The impression gained is that although the Indian Muslim is a great fat eater, other Indians, particularly the Tamils from the South do not eat much more, if as much, fat as the Chinese or Malay, who have a much lower incidence of coronary heart disease.

\section{Summary AND CONCLUSIONS}

The morbid anatomy of coronary heart disease, as it occurred in 552 persons of various races in Singapore, is described. In general, it is found to be the same, once developed, for each race, and to be much the same as elsewhere in the world. Minor racial differences are noted such as the low 
incidence of right coronary artery thrombosis in the Indian compared with the Chinese, and the generally more fulminating nature of the disease in the Indian Muslim.

The majority of those dying from coronary heart disease do so before attaining the age of 50 years: in the Occident the reverse obtains.

Major racial differences are shown to exist in the incidence of coronary heart disease; the Indian Muslim being twenty times, and the Indian ten times, more liable to die from this disease than the Chinese or Malay.

The sex incidence of coronary heart disease in Chinese women in Singapore is found to be the same as in the West, but the age incidence appears different.

Evidence is presented to suggest that the incidence of coronary heart disease in Singapore, and in neighbouring Malaya, is increasing.

A fall in mortality from coronary heart disease during the war years with a concomitant rise in the deficiency diseases, suggests that diet, as well as race, plays a part in pathogenesis.

Certain features of coronary heart disease in India, China, Ceylon, and Africa are discussed.

I wish to thank Professor R. Kirk for kind help and criticism, Mr. V. Nalpon of this Department, for advice about racial dietary differences, Mr. Ti Teow See for Fig. 1, Mr. E. J. Phillips of the Singapore Government Department of Statistics for various data, my wife and Mr. P. A. Samuel for secretarial assistance.

\section{REFERENCES}

Bartels, E. C., and Smith, H. L. (1932). Amer. J. med. Sci., 184, 452.

Becker, B. J. P. (1946). S. Afr. J. med. Sci., 11, 97 and 107.

Bland, E. F., and White, P. D. (1951). Unpublished data quoted in Heart Disease, by P. D. White, 4th ed., p. 528. New York, The MacMillan Co.

Clawson, B. J. (1941). Amer. Heart J., 22, 607.

Cleland, J. B. (1949). Med. J. Aust, 2, 733.

Davidson, W. S. (1953). Med. J. Aust, 1, 584.

Davies, J. N. P. (1948). E. Afr. med. J., 25, 454.

Denny, F. P. (1936). New Engl. J. Med., 214, 769.

Foster, T. H. (1930). New Engl. J. Med., 203, 1073.

Friedberg, C. K., and Sohval, A. R. (1949). Unpublished observations, quoted in Diseases of the Heart, by C. K. Friedberg, p. 421, Philadelphia, Saunders.

Hannah, J. B. (1958). Central Afr. med. J., 4, 1.

Hedley, O. F. (1939). Ann. intern. Med., 13, 598.

Hellerstein, H. K., and Martin, J. W. (1947). Amer. Heart J., 33, 443.

Holoubeck, A. G. (1945). Amer. Heart J., 29, 168.

Houston, W. H. (1928). Med. Clin. N. Amer., 12, 1285.

Jayewardene, R. P., and Jayesekere, H. T. W. (1954). Ceylon med. J., 2, 163.

Johnston, C. (1936). Amer. Heart J., 12, 162.

Malmros, H. (1950). Acta med. Scand., suppl., 246, 137.

Marsden, A. T. H. (1957). In Annual Report of the Institute for Medical Research, Kuala Lumpur, Malaya, for 1955, p. 56.

Master, A. M. (1954). Amer. Heart J., 47, 321.

, Dack, S., and Naffe, H. L. (1937). J. Amer. med. Ass., 109, 546.

Muir, C. S. (1958). Tran. Roy. Soc. Trop. Med. Hyg., 52, 446.

Müller, H. (1935). Meded. Dienst Volksgezondh. Ned.-Indië, 3, 176.

Peel, A. A. F. (1955). Brit. Heart J., 17, 319.

Phipps, C. (1936). J. Amer. med. Ass., 106, 761.

Ruffer (1921). Quoted by Hannah (1958).

Ryle, J. A., and Russell, W. T. (1949). Brit. Heart J., 11, 370.

Schornagel, H. E (1953). Docum. Med. geogr. trop. (Amer.), 5, 173.

Smith, C., Sauls, H. C., and Ballen, J. (1942). Ann. intern. Med., 17, 681.

Snapper (1941). Chinese Lessons to Western Medicine, p. 160. New York: Interscience Publishers.

Subrahmanyam, C. C. (1958). Personal communication.

Tung Chen-Lang (1948). Chinese med. J., 66, 587.

Vakil, R. J. (1949). Indian Heart J., 1, 201.

Wartman, W. B., and Hellerstein, H. K. (1948). Ann. intern. Med., 28, 41.

Weiss, M. M., and Gray, W. R. (1954). Amer. J. med. Sci., 227, 186.

White, P. D. (1951). Heart Disease. 4th edit., p. 530. New York, The MacMillan Co.

Wijeyesekera, J. G. (1954). Ceylon med. J., 2, 168.

Wood, P. (1956). Diseases of the Heart and Circulation. 2nd edit., London, Eyre and Spottiswoode.

Yater, W. M., Traum, A. H., Brown, W. G., Fitzgerald, R. P., Geisler, M. A., and Wilcox, B. B. (1948). Amer. Heart $J ., 36,334,481$ and 683 .

Zuidema, P. J. (1952). Docum. Med. geogr. trop. (Amer.), 4, 378. 